International Journal of Current Advanced Research

ISSN: O: 2319-6475, ISSN: P: 2319 - 6505, Impact Factor: SJIF: 5.995

Available Online at www.journalijcar.org

Volume 6; Issue 3; March 2017; Page No. 2488-2493

DOI: http://dx.doi.org/10.24327/ijcar.2017.2493.0034

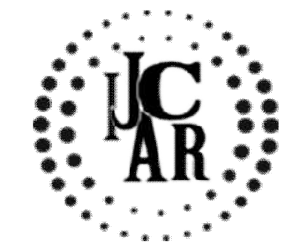

Research Article

\title{
CLINICO-EPIDEMIOLOGICAL AND ANTHROPOMETRIC PROFILE OF RURAL PRESCHOOL CHILDREN IN CENTRAL KERALA
}

\author{
Priyanka R${ }^{1}$, Jubina Bency A T ${ }^{2}$, , Vivin Vincent ${ }^{3}$ and C R Saju ${ }^{4}$
}

${ }^{1,2}$ Department of Community medicine, Jubilee Mission Medical College and Research Institute, Thrissur, Kerala, India

3,4 Department of Community medicine, Amala Institute of Medical Sciences, Thrissur, Kerala, India

\section{A R T I C L E I N F O}

\section{Article History:}

Received $8^{\text {th }}$ December, 2016

Received in revised form $19^{\text {th }}$ January, 2017

Accepted $12^{\text {th }}$ February, 2017

Published online $28^{\text {th }}$ March, 2017

\section{Key words:}

Anthropometric profile, pre-school children, underweight, stunting

\begin{abstract}
A B S T R A C T
Background: Nutritional status of children below the age of five years is a sensitive indicator of the overall development of the community. Under-nutrition among under-five children is one of the greatest public health problems in developing countries. According to UNICEF, in India, around 46 per cent of all children below the age of three are too small for their age, 47 per cent are underweight and at least 16 per cent are wasted. Many of these children are severely malnourished. The objective of the present study is to determine the epidemiological, clinical, and anthropometric profile of rural preschool children.

Materials and methods: A cross sectional study was conducted among 360 under-five children in five selected wards (clusters) of Varandarapilly panchayath in Thrissur district. After getting written informed consent from the parents, they were interviewed using pretested semi structured interview schedule. The questionnaire covered the socio-demographic characteristics, dietary practices, and morbidity profile of children. For assessing nutritional status, clinical examination and measurement anthropometric measurements like, height, weight, mid-upper arm circumference, head circumference and chest circumference of the children were done using standard protocols.

Results: Mean age of the study population was found to be $33.61 \pm 16.15$ months. There were 176(48.9) males and 184(51.1) females in the study. The overall prevalence of under-weight was found to be $28.3 \%$ and that of stunting $14 \%$. There were $49(13.6 \%)$ children in the study group who were both under-weight and stunted. The proportion of underweight and stunting was found to be higher among females than among males. The calorie consumption was not adequate $(<80 \%$ of RDA) in majority $(66.9 \%)$ of the children in the study group. $58.1 \%$ children were consuming a diet which was inadequate in protein. Clinical examination of study subjects showed that $196(54.4 \%)$ children had one or the other clinical signs of nutritional deficiency.

Conclusion: The present study showed a moderately high prevalence of underweight and stunting among the under-five children, with a clear gender difference in their anthropometric profiles. The dietary consumption of calories and proteins were far below requirement, which is clinically manifested as macronutrient and micronutrient deficiency in the study group.
\end{abstract}

Copyright $\mathrm{C} 2017$ Priyanka $\boldsymbol{R}$ et al. This is an open access article distributed under the Creative Commons Attribution License, which permits unrestricted use, distribution, and reproduction in any medium, provided the original work is properly cited.

\section{INTRODUCTION}

Children below the age of five years constitute the most vulnerable segment of the community. Their nutritional status is a sensitive indicator of the overall development of the community. Under-nutrition among under-five children is one of the greatest public health problems in developing countries. ${ }^{1}$ Lack of proper nutrition jeopardizes children's survival, growth and development, and it slows national progress towards achieving development goals. Undernutrition is often an invisible and silent emergency. ${ }^{2}$ According to UNICEF, in India, around 46 per cent of all children below the age of three are too small for their age, 47 per cent are underweight and at least 16 per cent are wasted. Many of these children are severely malnourished. ${ }^{3}$

*Corresponding author: Priyanka R

Department of Community medicine, Jubilee Mission Medical College and Research Institute, Thrissur, Kerala, India

\section{Macronutrient and micronutrient deficiencies}

Macronutrient deficiencies occur when the body adapts to a reduction in macronutrient intake by a corresponding decrease in activity and an increased use of reserves of energy (muscle and fat), or decreased growth. Consequently, malnourished individuals can be shorter, or thinner than their well nourished counter-parts. ${ }^{4} \quad$ 'Hidden Hunger', or micronutrient malnutrition, is widespread in developing countries. It occurs when essential vitamins and/or minerals are not present in adequate amounts in the diet.

The most common micronutrient deficiencies relate to iron (anemia), vitamin A (xerophthalmia, blindness), and iodine (goiter and cretinism). Others, such as vitamin C (scurvy), niacin (pellagra), and thiamin or vitamin B1 (beriberi), also can occur during acute or prolonged emergencies when populations are dependent on a limited, unvaried food source. $^{4}$ 


\section{Anthropometric indices}

Anthropometry is defined as the measurement of physical dimensions and gross composition of the body (height, weight, mid-upper arm circumference etc.).The degree of malnutrition is defined by cut-off points; and the individuals falling below a specific cut-off point are classified with a specific degree of malnutrition. ${ }^{5}$ In children, the three most commonly used anthropometric indices are weight for age, height for age and weight for height. These anthropometric indices can be expressed in terms of standard deviation scores ( $Z$ scores), which can then be used to compare a child or a group of children with a reference population. ${ }^{6}$

\section{Standard deviation scores (Z scores)}

For consistency with clinical screening, prevalence-based data are commonly reported using a cut-off value, often $<-2$ and $>$ +2 Z-scores. The $Z$-score system expresses anthropometric values as several standard deviations (SDs) below or above the reference mean or median value. ${ }^{7}$

The rationale for this is the statistical definition of the central $95 \%$ of a distribution as the "normal" range, which is not necessarily based on the optimal point for predicting functional outcomes. ${ }^{7}$

Once a child's height and weight have been correctly measured and their age has been recorded, a clinician or researcher can assess the child's growth and general nutritional status by using a standardized age-specific and sex-specific growth reference to calculate height-for-age $Z$ scores (HAZ), weight-for-age $Z$-scores (WAZ), and weightfor-height $Z$-scores (WHZ). ${ }^{8}$

$\mathrm{Z}$ score or standard deviation score is the deviation of the value for an individual from the median value of the reference population, divided by the standard deviation for the reference population. ${ }^{8}$

(Observed value) - (median reference value)

$\mathrm{Z}$ score or SD score $=$ Standard deviation of the reference population
S

\section{Definitions of anthropometric indicators}

Anthropometry can identify three forms of growth failure (under-nutrition): under-weight (low weight for age), stunting (low height for age) and wasting (low weight for height)

\section{Under-weight (low weight for age)}

Low weight for age is defined as the percentage of children aged 0 to 59 months whose weight for age is below minus two standard deviations (moderate under-weight) and minus three standard deviations (severe under-weight) from the median of the WHO Child Growth Standards. 7,9

\section{Stunting (low height for age)}

It is defined as the percentage of children aged 0 to 59 months whose height for age is below minus two standard deviations (moderate stunting) and minus three standard deviations (severe stunting) from the median of the WHO Child Growth Standards. ${ }^{9}$

\section{Wasting (low weight for height)}

It is defined as the percentage of children aged 0 to 59 months whose weight for height is below minus two standard deviations (moderate wasting) and minus three standard deviations (severe wasting) from the median of the WHO Child Growth Standards. ${ }^{9}$

\section{Clinical assessment of nutritional status}

Clinical assessment of nutritional status involves assessing the physical presentation of signs and symptoms of acute malnutrition, such as visible wasting and bilateral edema or fluid retention on both sides of the body. ${ }^{8}$ Other signs of malnutrition are: pallor, glossitis, angular stomatitis, cheilosis, corneal vascularization, follicular and other lesions of skin. These may be caused by deficiency of more than one nutrient. ${ }^{10}$

\section{Dietary assessment of nutritional status}

Dietary assessment involves assessing the food intake of individuals over a specific period of time (e.g. 24 hours, 7 days) and comparison of overall intake to daily allowances. ${ }^{8}$

\section{Impact of Malnutrition on Health and Development of under-five children}

Malnourished children experience developmental delays, weight-loss and illness as a result of inadequate intake of protein, calories and other micronutrients. Malnutrition in early child hood has short-term and long-term complications. Short term implications include impact on immunity and growth. Malnourishment can greatly compromise a child's immune system, making them more susceptible to infectious diseases. Particularly in places where there are poor sanitary practices, children are vulnerable to infections from other children or caregivers. In particular, zinc, iron and vitamin A are commonly associated with weakened immune function. ${ }^{11}$

The short-term implications of malnutrition eventually give way to long-term complications, such as growth and cognitive delays. Malnutrition not only impacts growth in the short term, but can also limit total bone growth. Additionally, children classified as low height-for-age (stunted) may never be able to regain lost growth potential if they continue to live in a nutritionally deprived situation. Malnutrition negatively effects brain development causing delays in motor and cognitive development, such as: Attention deficit disorders, impaired school performance, decreased IQ scores, memory deficiency, learning disabilities, and reduced social skills. ${ }^{11}$

When human potential and resources are trapped in the vicious cycle of malnutrition, development goals and improved standards of living will not be realized. Hence, the International Conference on nutrition (ICN) recommended that nutrition be at the centre of socio-economic development plans and strategies of all countries (FAO/WHO, 1992). ${ }^{12}$ The present study is an attempt to analyze the clinical, epidemiological and anthropometric profile of preschool children in a rural area of Thrissur district, as the preschool children living in rural areas are vulnerable and at a disadvantageous position compared to their urban counterparts regarding their nutritional achievements.

\section{Aim \& Objective}

To study the epidemiological, clinical, and anthropometric profile of rural preschool children.

\section{MATERIALS AND METHODS}

A community based cross sectional study was conducted among children aged $0-5$ years in five selected wards 
(clusters) of Varandarapilly panchayath in Thrissur district. Sample size was calculated by taking the prevalence of malnutrition among pre-school children in rural Kerala as $34.8 \%$ (National Nutrition Monitoring Bureau-NNMB Rural Survey-Kerala-2003-06). As cluster sampling method was used, design effect (D) was taken into account, and sample size was calculated to be 360 . Study was initiated after obtaining ethical clearance from the Institutional ethics committee. After getting written informed consent from the parents, they were interviewed using pretested semi structured interview schedule. The questionnaire covered the sociodemographic characteristics, dietary practices, and morbidity profile of children. For assessing nutritional status, clinical examination and measurement anthropometric measurements like, height, weight, mid-upper arm circumference, head circumference and chest circumference of the children were done. Weight was measured using an electronic weighing machine (Salter scale for children less than two years) to the nearest of $0.1 \mathrm{~kg}$. Height/length was measured using stadiometer to the nearest $0.1 \mathrm{~cm}$.

\section{Data analysis}

The data was collected, coded and entered into Microsoft Excel. Using WHO Anthro plus software, the Weight for age and Height for age Z scores were calculated. The WHO 2006 cut off points ( $-2 \mathrm{SD}$ or less than $-2 \mathrm{SD}$ from the median) were used to assess the degree of under-weight and stunting. After getting the standard deviation of underweight and stunting, the whole data was rechecked and analyzed using SPSS statistical software.

\section{RESULTS}

\section{Epidemiological Profile of the Study Subjects}

Mean age of the study population was found to be $33.61 \pm$ 16.15 months; Median age was found to be 36 months and the age of the study group ranged from 3 months to 60 months. There were 176(48.9) males and 184(51.1) females in the study. Majority of the children in the study were Hindus (52.5\%), followed by Muslims (32.8\%).

Table 1 Epidemiological profile of study subjects

\begin{tabular}{ccc}
\hline Variable & $\begin{array}{c}\text { Number } \\
(\mathbf{N}=\mathbf{3 6 0})\end{array}$ & Percentage \\
\hline Age (months) & 118 & 32.8 \\
$0-23$ & 242 & 67.2 \\
$24-60$ & & \\
Sex & 176 & 48.9 \\
Male & 184 & 51.1 \\
Female & & \\
Religion & 189 & 52.5 \\
Hindu & 53 & 32.8 \\
Christian & 118 & 14.7 \\
Muslim & & \\
Maternal education & 155 & 43.1 \\
Lower than higher & 205 & 56.9 \\
secondary & 191 & $53.1 \%$ \\
Higher secondary \& above & 169 & $46.9 \%$ \\
Socioeconomic status & & \\
Upper \& middle class & 38 & $10.6 \%$ \\
Lower class & 322 & $89.4 \%$ \\
Working status of mother & &
\end{tabular}

The proportion of children who belonged to Christian community was $14.7 \%$. There were 205 (57\%) mothers who were educated up to higher secondary school. Majority of the mothers, $322(89.4 \%)$ were housewives and 38 (10.6\%) were working mothers. There were 191 (53.1\%) children who belong to middle and upper socioeconomic class and 169 (46.9\%) from lower class, according to Modified B.G Prasad's classification. (Table:1)

Mean birth weight of the study group was found to be $2.851 \pm$ $0.46 \mathrm{Kg}$. There were 69(19.2) children who were born with a low birth weight. There were $77(21.4 \%)$ children who had complications soon after birth, and the most common complication in the study group was neonatal jaundice. 45 children $(12.5 \%)$ had history of neonatal jaundice and 27 children (7.5\%) had history of breathing difficulty. 5 (1.4\%) children had fever/sepsis after birth. (Fig:1)

In this study, $91.1 \%$ children were fully immunized, and $8.9 \%$ were partially immunized. None of the children in the study group was un-immunized.

\section{Dietary Practices of the Study Subjects}

Exclusive breast feeding was given to $240(66.7 \%)$ children. In this study it was found that, $65(18.1 \%)$ children were given bottle feeding, (any time during their infancy/childhood) which is an important risk factor for acute diarrheal diseases in children. Bottle feeding was mostly used for giving diluted cow's milk and infant milk substitutes. Complementary feeding was started by majority $(68 \%)$ of children at the age of 6-9 months. There were $32 \%$ children who started on complementary feeds before the age of 6 months. Type of complementary feeds used were homemade foods like like ragie, wheat, and rice in 214(60.6) of children. There were 25(7.1) children who were given commercially available artificial feeds like Cerelac, Nan or baby vita as complementary feeds.

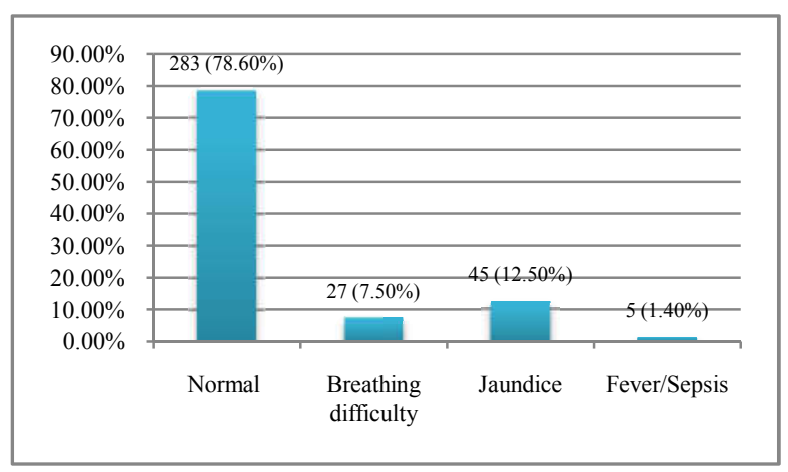

Fig 1 Type of complications soon after birth among the study subjects

The mean calorie intake of the study population is $1187.26 \pm$ $217.02 \mathrm{Kcal}$. The minimum calorie intake was $574 \mathrm{Kcal}$ and maximum was $1728 \mathrm{Kcal}$. The calorie consumption was not adequate $(<80 \%$ of RDA) in majority, $(66.9 \%)$ of the children in the study group. Only $33.1 \%$ of the children in the study were consuming adequate calories through their daily diet.

The mean protein intake of the study population is $21.58 \pm 3.9$ gm. The minimum protein intake was $10 \mathrm{gm}$ and maximum was $32 \mathrm{gm}$. Protein intake was adequate in $41.9 \%$ of the children. $58.1 \%$ children were consuming a diet which was inadequate in protein. The daily calorie and protein intake is found to have a positive correlation with the weight of the children in the study group. (Fig:2) 

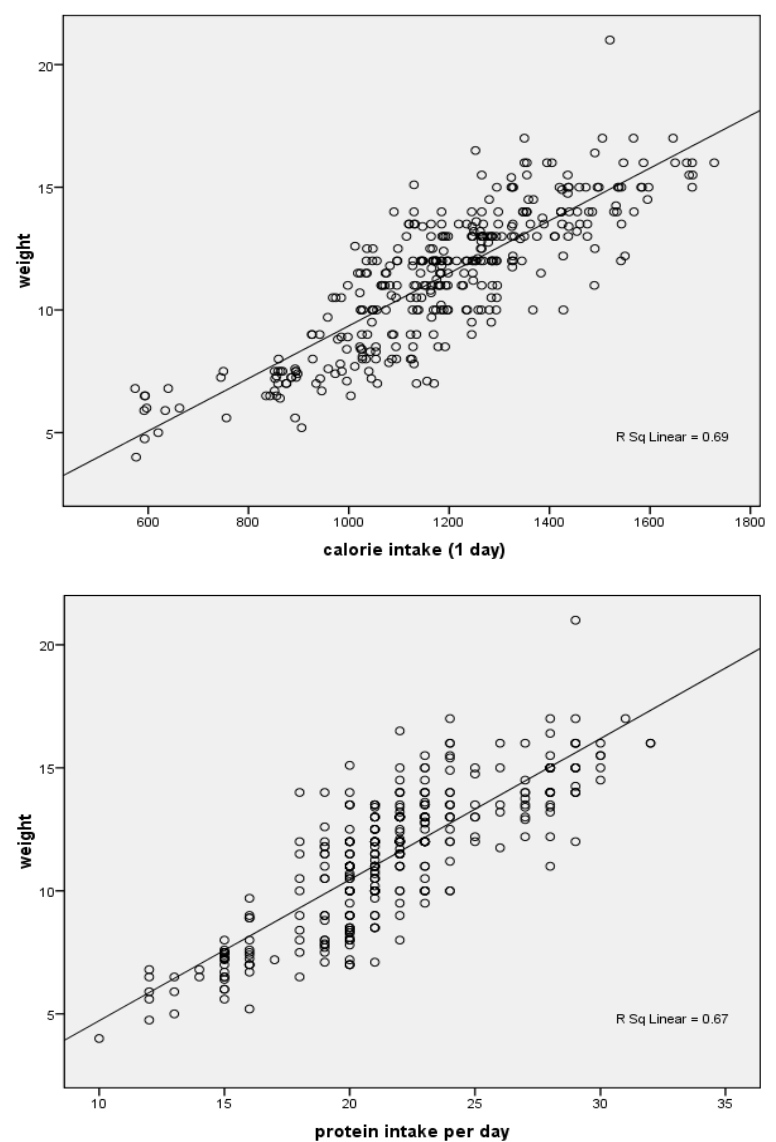

Fig 2 Correlation between daily calorie and protein intake and weight of study subjects

\section{Anthropometric Profile of the Study Subjects}

The mean height of the population was found to be $86.44 \pm$ $11.85 \mathrm{~cm}$. Mean height of males was $87.68 \pm 10.96 \mathrm{~cm}$ and that of females was $85.2 \pm 12.56 \mathrm{~cm}$. The difference between the mean heights of males and females was found to be statistically significant ( $\mathrm{t}$ test; $\mathrm{p}=0.045$ )

The mean weight of the study population was found to be $11.36 \pm 2.79 \mathrm{~kg}$. The mean weight of the male children was found to be $11.86 \pm 2.75 \mathrm{~kg}$ and female children $10.88 \pm 2.76$ $\mathrm{kg}$. The difference between weights of male and female children were found to be statistically significant $(\mathrm{t}$ test; $\mathrm{p}=0.001)($ Fig:3)

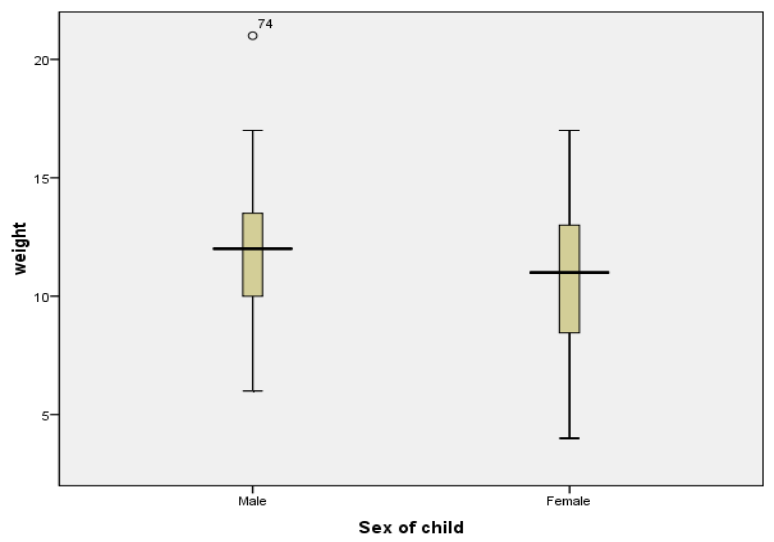

Fig 3 Gender-wise comparison of weight of study subjects

Out of the 360 under five children studied, under weight (Weight for age $<-2 \mathrm{SD}$ ) was found in 102 children. The overall prevalence of under-weight was found to be $28.3 \%$ $(95 \% \mathrm{CI}=23.7-33.01)$. The overall prevalence of stunting was found to be $14 \%(95 \% \mathrm{CI}=10.3-17.5)$. There were 49 $(13.6 \%)$ children in the study group who were both underweight and stunted. The prevalence of moderate under-weight (WFA Z score $<-2$ SD to $\geq-3$ SD) was found to be $22.2 \%$ and severe under-weight (WFA $Z$ score $<-3 \mathrm{SD}$ ) was found to be $6.1 \%$. The prevalence of moderate stunting (HFA Z score $<-$ $2 \mathrm{SD}$ to $\geq-3 \mathrm{SD})$ was found to be $10.3 \%$ and severe stunting (HFA $\mathrm{Z}$ score $<-3 \mathrm{SD}$ ) was found to be $3.7 \%$ in the present study. The rate of under-weight among females was found to be higher (32.6\%) in this study. Among the male children, the rate of under-weight was found to be $23.9 \%$. The prevalence of stunting was found to be higher in females $(16.3 \%)$. The prevalence of stunting among males was found to be $11.4 \%$.

The distribution of under nourished children stratified by sex is shown in the following figure (Fig:4)

Out of the 292 under-five children (those aged $13-60$ months), 34 (11.7\%) were malnourished and $258(88.3 \%)$ were found to be normal based on their mid upper arm circumference. The mean mid upper arm circumference of males was $14.73 \pm 0.99 \mathrm{~cm}$, and that of females was $14.60 \pm$ $1.01 \mathrm{~cm}$. The difference was not statistically significant ( $\mathrm{t}$ test; $\mathrm{p}=0.273$ )

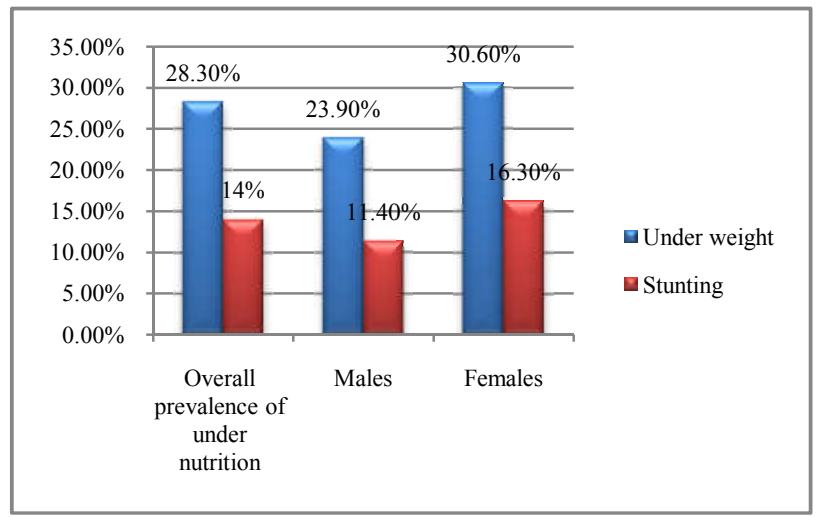

Fig 4 Distribution of under nourished children stratified by sex

The mean head circumference of children was found to be $47.27 \pm 2.52 \mathrm{~cm}$. The mean head circumference of male children was $48.05 \pm 2.31 \mathrm{~cm}$ and that of females was $46.52 \pm$ $2.48 \mathrm{~cm}$. There was a significant difference between the head circumference of male and female children ( $t$ test; $p=0.0001$ ). The mean chest circumference of the study population was $48.42 \pm 3.52 \mathrm{~cm}$. The mean chest circumference of male children was $49.17 \pm 3.34 \mathrm{~cm}$, and that of female children was $47.70 \pm 3.54 \mathrm{~cm}$. There was a statistically significant difference between the chest circumference of male and female children. ( $\mathrm{t}$ test; $\mathrm{p}=0.0001$ ).

\section{Clinical Profile of the Study Group}

There were 34 (9.4\%) children who had more than 3 episodes of illness in the past year. The rest of the children 326 $(90.6 \%)$ had three or less than 3 episodes of illness in the past year, out of which $21(5.8 \%)$ did not suffer from any illness in the past one year.

89 children $(24.7 \%)$ had history of acute respiratory tract infection and $73(20.3 \%)$ had history of acute diarrheal disease in the past one year. There were $92(25.5 \%)$ children 
with skin diseases (dermatitis/rashes/fungal infection) and 14 (3.9\%) with dental caries. (Fig:5)

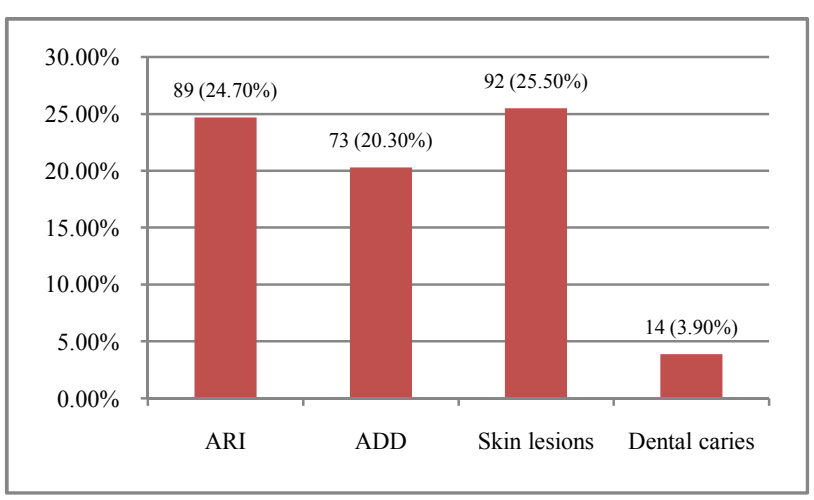

Fig 5 Type of illness suffered by study subjects in the past one year

At the time of survey, children were examined for clinical signs of nutritional deficiencies. It was found that 196 $(54.4 \%)$ children had one or the other signs of nutritional deficiency. $164(45.6 \%)$ children did not show any nutritional deficiency signs. On clinical examination of the under-five children it was found that $152(42.2 \%)$ had pallor. There were $80(22.2 \%)$ children who had hypo-pigmented skin patches and $5(1.4 \%)$ with oral ulcers. Dry skin was seen in $4(1.1 \%)$ and bowing of legs in 5 (1.4\%). (Fig:6)

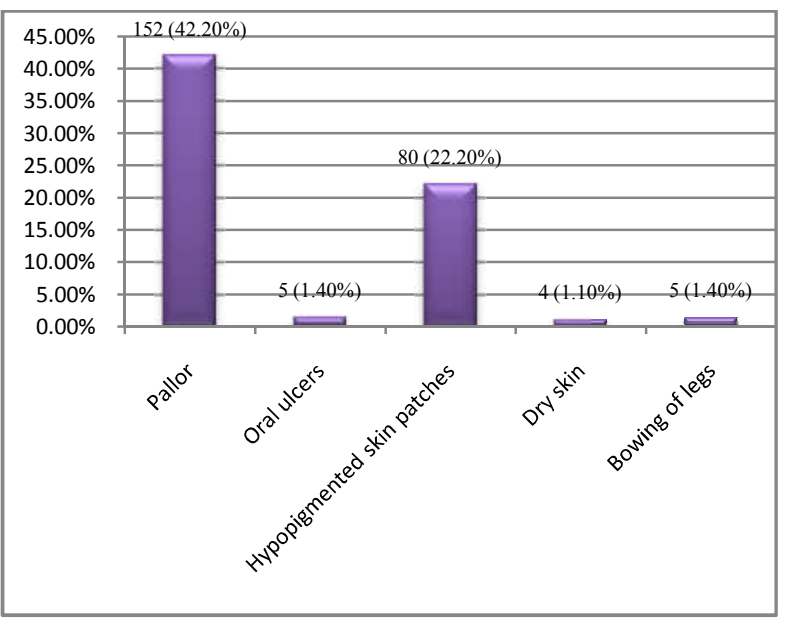

Fig 6 Type of nutritional deficiency signs among the study subjects

There were $153(42.5 \%)$ children in the study who had symptoms (as told by the mothers) of worm infestation, such as peri-anal itching/passage of worms in stools. The rest of the children 207 (57.5\%) did not have any symptoms of worm infestation.

\section{DISCUSSION}

In this study, mothers of the under-five children were found to be highly educated. This is consistent with the high literacy rate of females in Kerala. According to the Census 2011, the total literacy rate in Thrissur district is $95.08 \%$ and male literacy rate is $96.78 \%$ and female literacy rate is $93.56 \%{ }^{13}$ The proportion of low birth weight children in this study $(19.2 \%)$, is similar to that found in a study done by $\mathrm{T}$. Radhakrishnan et al in rural area of Trivandrum, which was found to be $17.9 \% .{ }^{14}$ The present study found that the prevalence of underweight and stunting is higher among female children as compared to male children. This is consistent with the study done by Aswini Kumar et al, in rural
Karnataka, where it was found that girls $(46.2 \%)$ were more malnourished than boys $(33.6 \%){ }^{15}$

The prevalence of malnutrition based on the mid upper arm circumference of study subjects was $11.7 \%$, which is almost similar to that of a study by Vijayasree Mathad et al, among under fives in rural Karnataka, in which the prevalence of malnutrition by mid upper arm circumference was found to be $13.79 \%$ among children in the age group $13-60$ months. ${ }^{16}$ The significantly higher mean weight and height of males found in this study is similar to another study done by Biswas $\mathrm{S}$, et al, in Chapra, West Bengal, among pre-school children,where boys were found to be heavier and taller than girls. $^{17}$

On clinical examination of the under-five children it was found that $152(42.2 \%)$ had pallor. There were $80(22.2 \%)$ children who had hypo-pigmented skin patches and $5(1.4 \%)$ with oral ulcers. Dry skin was seen in $4(1.1 \%)$ and bowing of legs in $5(1.4 \%)$. In a study done by Srinivasan $\mathrm{K}$ et al, in Tirupati, nutritional deficiency signs like skin disorders and anemia were found in $29.9 \%$ and $79.6 \%$ of children respectively. ${ }^{18}$ In a study done by Barkha Sharma et al, in Madhya Pradesh, it was reported that angular stomatitis was found in $32.5 \%$, and cheilosis was found in $20.3 \%{ }^{19}$

Inadequate calorie intake was found in $66.9 \%$ of the underfive children in the present study. A similar study by Sandip Kumar Ray et al, it was found that $47.8 \%$ of the study population is deprived of the required minimum calories. ${ }^{20}$ Protein intake was adequate only in $41.9 \%$ of the children in the study group. A study done by Vijayasree Mathad et al in rural Karnataka also showed that only $56.5 \%$ of the children are getting the adequate protein through their diet. ${ }^{16}$

\section{CONCLUSION}

The present study showed a moderately high prevalence of underweight and stunting among the under-five children, with a clear gender difference in their anthropometric profiles. Even though the proportion of children who were exclusively breast fed was found to be high, their daily dietary calorie and protein consumption were far below the requirement. The clinical profile of the study subjects were also far from satisfactory, with a higher proportion of them showing nutritional deficiency signs. It may be concluded that adequate care of newborns and infants; exclusive breast feeding, appropriate complementary feeding and dietary practices, and full immunization of children, will help to improve the anthropometric profile of under-five children.

Funding: No funding sources Conflict of interest: None declared

Ethical approval: The study was approved by the Institutional Ethics Committee

\section{References}

1. Sachdev HPS: Assessing child malnutrition - Some basic issues. Bull Nutrition Foundations India 1995; Vol.16: p. 1-5

2. Final Report \& Recommendations: Malnutrition Monitoring Committee, 2007- 2012. Available from: http://www.mahaarogya.gov.in/Malnutrition/Absolutel y\%20Final\%20report\%20Malnutrition\%20492012.pdf

3. UNICEF India: The children-Nutrition. Available from: http://www.unicef.org/india/children_2356.htm 
4. A Manual: Measuring and interpreting malnutrition and mortality - Defining and measuring malnutrition. Centre for Disease Control and World Food Programme. UNHCR operational publications 2007; p.15-17

5. Jelliffe D.B. The Assessment of the Nutrition Status of the Community: Geneva, World Health Organization (Monograph Series No. 53). p. 271

6. World Health Organization - Physical status: The use and Interpretation of anthropometry. Report of WHO Expert Committee. Technical Report Series No. 854, Geneva, WHO, 1995

7. WHO Multicentre Growth Reference Study Group: WHO Child Growth Standards, Methods and development. Geneva, WHO, 2006. Available from: http://www.who.int/childgrowth/standards/technical_ report/en/ index.html

8. World Health Organization Module 6 - Measuring malnutrition: Individual assessment of acute malnutrition, Technical notes. HTP Version 2, 2011; Available from: http:/www.unicef.org/nutritioncluster/ files/Module6MeasuringMalnutritionIndividualAssess mentTechnicalNotes.pdf

9. Improving Child Nutrition: The Achievable Imperative for Global Progress UNICEF Publications, April 2013.

10. World Health Organization - Expert committee on medical assessment of nutritional status. Technical Report Series 258, WHO, Geneva

11. Impact of malnutrition on health and development, Orphan Nutrition - An initiative of a child's best start to improve nutrition and feeding of orphaned children. Available at: http://www.orphannutrition.org/ under standing-malnutrition/impact-of-malnutrition-on-health -and-development

12. Incorporating Nutrition Considerations into Development Policies and Programmes:

13. Brief for Policy-makers and Programme Planners in developing countries; Nutrition Planning, Assessment and Evaluation service, Food and Nutrition Division, Food and Agriculture Organization of the United Nations, ROME, 2004
14. Census India 2011 - Provisional Population Totals India-data sheet. Office of the Registrar General and Census Commissioner, India. Available from: http://censusindia.gov.in/2011-prov-results/paper2/ prov_results_paper2 india.html

15. Radhakrishnan T, Thankappan K R, Vasan R S, Sarma $\mathrm{P}$ S. Socio-economic and demographic factors associated with low birth weight: A community study in Kerala. Available from: www.indianpediatrics.net/ august2000/august_872_876 htm

16. Kumar A, Kamath A, Kamath V.G, Rao A, Pattanshetty C R, Sagir S, Afrin et al. Nutritional status assessment of under-five beneficiaries of Integrated Child Development Services program in rural Karnataka. Australasian Medical Journal AMJ 2010; 8 (3): p.495-98

17. Mathad V, Matqud C, Mallapur M D. Nutritional Status of Under Fives In Rural Area Of South India. Indian Journal Of Medical Sciences April 2011; 65 (4): p. 151-56Biswas S, Bose K, Mukhopadhyay A, Bhadra M. Prevalence of under nutrition among pre-school children of Chapra, Nadia District, West Bengal, India, measured by composite index of anthropometric failure (CIAF). Anthropol Anz Sep 2009; .67 (3): p.269-79.

18. Srinivasan K, Prabhu G K. A study of the morbidity status of children in social welfare hostels in Tirupati town. Indian Journal of Community Medicine Sep 2006; 31 (3): p.170-72

19. Sharma B, Mitra M, Chakrabarthy S, Bharati P. Nutritional status of pre-school children of Raj Gond A tribal population in Madhya Pradesh, India. Malasian Journal of Nutrition 2006; 12 (2): p.147-55

20. Ray S K, Biswas A B, Gupta S D, Mukherjee D. Rapid assessment of nutritional status and dietary pattern in Municipal area: Indian Journal of Community Medicine. 25 (1): (200-01-200-03)

\section{How to cite this article:}

Priyanka R et al (2017) ' Clinico-Epidemiological And Anthropometric Profile Of Rural Preschool Children In Central Kerala', International Journal of Current Advanced Research, 06(03), pp. 2488-2493.

DOI: http://dx.doi.org/10.24327/ijcar.2017.2493.0034 